\title{
PU.1 supports TRAIL-induced cell death by inhibiting NF-kB-mediated cell survival and inducing DR5 expression
}

\author{
Aladin Haimovici ${ }^{1}{ }^{2}$, Magali Humbert ${ }^{1}$, Elena A Federzoni ${ }^{3}$, Deborah Shan-Krauer ${ }^{1}$, Thomas Brunner ${ }^{4}$, Steffen Frese ${ }^{5}$, \\ Thomas Kaufmann ${ }^{6}$, Bruce E Torbett ${ }^{3}$ and Mario P Tschan ${ }^{\star, 1,2}$
}

The hematopoietic Ets-domain transcription factor PU.1/SPI1 orchestrates myeloid, B- and T-cell development, and also supports hematopoietic stem cell maintenance. Although PU.1 is a renowned tumor suppressor in acute myeloid leukemia (AML), a disease characterized by an accumulation of immature blast cells, comprehensive studies analyzing the role of PU.1 during cell death responses in AML treatment are missing. Modulating PU.1 expression in AML cells, we found that PU.1 supports tumor necrosis factor-related apoptosis-inducing ligand (TRAIL)-mediated apoptosis via two mechanisms: (a) by repressing NF- $\kappa$ B activity via a novel direct PU.1-RelA/p65 protein-protein interaction, and (b) by directly inducing TRAlL receptor DR5 expression. Thus, expression of NF-kB-regulated antiapoptotic genes was sustained in PU.1-depleted AML cells upon TRAIL treatment and DR5 levels were decreased. Last, PU.1 deficiency significantly increased AML cell resistance to anthracycline treatment. Altogether, these results reveal a new facet of PU.1's tumor suppressor function during antileukemic therapies.

Cell Death and Differentiation (2017) 24, 866-877; doi:10.1038/cdd.2017.40; published online 31 March 2017

The Ets-domain transcription factor PU. 1 is key to myeloid and B-cell development as well as to hematopoietic stem cell maintenance by controlling differentiation, proliferation and survival of these cells. During myelopoiesis PU.1 activates a large number of genes directly involved in myeloid differentiation and maturation. ${ }^{1-3}$ Importantly, PU.1 levels are crucial for the determination of the different hematopoietic lineages. ${ }^{4}$ In malignant hematopoiesis deregulated elevated PU.1 expression causes erythroleukemia in mice, whereas reduced PU.1 expression leads to leukemia and lymphomas. ${ }^{3}$ In line with these findings in mice, low PU.1 levels are found in undifferentiated human acute myeloid leukemia (AML), particularly in acute promyelocytic leukemia (APL) where PU.1 is transcriptionally repressed by the PML-RARA fusion protein. $^{5,6}$

In addition to its role in controlling myeloid differentiation, PU.1 directly or indirectly regulates genes implicated in apoptosis and proliferation. For instance, PU.1 can attenuate Bim's proapoptotic activity by directly inducing MEIS1 positively affecting AML cell proliferation. ${ }^{7}$ Moreover, PU.1 directly activates antiapoptotic Bcl-2A1 to support cell survival during neutrophil differentiation. ${ }^{8}$ The role of PU.1 can be extended to the commitment and maintenance of stem cells trough regulating the transcription of several cell cycle regulators. ${ }^{9}$ Recently, we linked PU.1 to the intracellular degradation process autophagy during retinoic acid-induced neutrophil differentiation of AML cells. ${ }^{10-12}$ Taken together, these reports clearly highlight the importance and versatility of this transcription factor in regulating apoptotic and cell cycle genes in a context-dependent manner.

Tumor necrosis factor-related apoptosis-inducing ligand (TRAIL) is a promising anticancer drug because of its capacity to induce apoptosis selectively in cancer cells. ${ }^{13}$ TRAIL is a member of the TNF family of death ligands and binds to the four major receptors TRAIL-R1-4. Binding to TRAIL-R1 (DR4) and TRAIL-R2 (DR5) induces apoptosis signaling, whereas binding to TRAIL-R3 (DcR1) and TRAIL-R4 (DcR2) can impair apoptosis signaling and activate alternative, non-apoptotic pathways. ${ }^{14,15}$ TRAIL binding to DR4 and DR5 triggers the formation of the death-inducing signaling complex (DISC), characterized by the recruitment of the adaptor protein FADD and caspase-8, which then induce the activation of downstream effector caspases. ${ }^{16}$ Resistance of cancer cells to TRAIL monotherapy is commonly found and includes increased expression of antiapoptotic genes such as the $\mathrm{NF}-\kappa \mathrm{B}$ target genes cellular FLICE-inhibitory protein $(c F L I P)$, $\mathrm{BCl}-2$ and $\mathrm{Mcl}-1 .^{17-20}$ Alternatively, upregulation of decoy receptor expression (TRAIL-R3) paralleled by NF- $\kappa$ B pathway activation increases resistance to TRAIL. ${ }^{21,22}$

To date, the function of PU. 1 in leukemia therapy other than differentiation therapy in APL has not been investigated in detail. We found that PU.1 enhances cell death responses to TRAIL and anthracycline treatment. Mechanistically, PU.1 was found to inhibit NF- $k$ B signaling by its interaction with RelA/p65 and thereby preventing the induction of antiapoptotic genes. Moreover, we identified DR5 as a critical transcriptional

${ }^{1}$ Division of Experimental Pathology, Institute of Pathology, University of Bern, Bern, Switzerland; ${ }^{2}$ Graduate School for Cellular and Biomedical Sciences, University of Bern, Freiestrasse 1, Bern, Switzerland; ${ }^{3}$ Department of Molecular and Experimental Medicine, The Scripps Research Institute, La Jolla, CA, USA; ${ }^{4}$ Chair of Biochemical Pharmacology, Department of Biology, University of Konstanz, Konstanz, Germany; ${ }^{5}$ Department of Thoracic Surgery, ELK Berlin Chest Hospital, Berlin, Germany and ${ }^{6}$ Institute of Pharmacology, University of Bern, Bern, Switzerland

${ }^{*}$ Corresponding author: MP Tschan, Division of Experimental Pathology, Institute of Pathology, University of Bern, Murtenstrasse 31, PO Box 62, Bern 3010, Switzerland. Tel: +41 31632 8780; Fax: 4131381 3412; E-mail: mario.tschan@ pathology.unibe.ch

Received 29.6.16; revised 28.2.17; accepted 02.3.17; Edited by J Silke; published online 31.3.2017 
target of PU.1 in response to TRAIL. Altogether, our studies identify PU.1 as a novel cell death regulator during AML therapy.

\section{Results}

PU.1 depletion increases the resistance to TRAILmediated apoptosis in AML cells. Based on the emerging role of PU.1 in physiological cell survival and apoptosis, we asked whether inhibiting PU.1 affects cellular fitness upon exogenous apoptosis stimulation by TRAIL treatment. We generated three different PU.1-knockdown AML cell lines, namely NB4, HL60 and MOLM-13 cells using two independent PU.1 targeting short hairpin RNA (shRNA) delivered by lentiviral vectors. PU.1-depleted and control-transduced AML cells were treated with human recombinant TRAIL for $24 \mathrm{~h}$. NB4 cells showed the lowest TRAIL sensitivity as compared with the other two AML cell lines and TRAIL concentrations for treatment were adapted to reach similar death responses (Supplementary Figures S1a-c; control cells). TRAIL treatment caused increased early apoptosis in control-transduced AML cells as evidenced by high levels of Annexin $\mathrm{V}^{+}$cells (35-45\%), whereas PU.1 depletion resulted in a significant reduction of Annexin $\mathrm{V}^{+}$cells (15-25\%) that prevailed at higher TRAIL concentrations (Figure 1a and Supplementary Figures S1a-d). In addition, all three AML PU.1-depleted cell lines showed a significant reduction in effector caspases activation as assessed by the caspase-3/7 activity (Figure $1 \mathrm{~b}$ and Supplementary Figure S1d; lower panel). These findings were not restricted to AML cells, and also extend to an REH B-cell precursor leukemia cell line (Supplementary Figure S1e).

Next, we determined cleaved caspase-8 and -3 , and cleaved PARP protein levels. Upon TRAIL treatment, NB4 and HL60 PU.1-depleted cells showed markedly reduced caspase-8 cleavage paralleled by increased procaspase-8 levels as compared with control cells (Figure 1c and Supplementary Figure S2a). Accordingly, PU.1-knockdown cells showed a marked reduction in caspase- 3 and PARP cleavage, confirming reduced apoptosis in PU.1-knockdown cells. These results were validated in MOLM-13 cells (Supplementary Figure S2b). Moreover, specifically inhibiting Bcl-2 by ABT-199 did only partially restore sensitivity of PU.1depleted AML cells to TRAIL in NB4 but not in HL60 cells, indicating that decreased PU.1 levels impact on TRAIL sensitivity mostly at the level of the DISC (Supplementary Figure S3). Altogether, we found impaired apoptosis responses to TRAIL in PU.1-depleted leukemic cells.

Decreased sensitivity to TRAIL in PU.1-depleted AML cells is associated with increased NF- $\kappa$ B activity. Given that TRAIL can induce alternative, prosurvival pathways such as NF- $k \mathrm{~B}$ signaling and since we observed reduced sensitivity to TRAIL-induced apoptosis in PU.1-knockdown cells, we hypothesized that depleting PU.1 activates NF- $k$ B signaling. To test this hypothesis, we transfected NB4 and HL60 cells with an NF-kB reporter plasmid. We found significantly increased NF- $\kappa$ B activity in PU.1-depleted AML as compared with control cells (Figure 2a). We next assessed whether cytoplasmic and nuclear protein lysates revealed a significantly pronounced nuclear translocation of p65 after $1 \mathrm{~h}$ of TRAIL stimulation in PU.1-depleted cells as compared with control NB4 cells (Figure 2b and Supplementary Figure S4). As AML PU.1-knockdown cells display increased NF- $k B$ activity, we speculated that blocking the NF- $\kappa B$ pathway restores TRAIL sensitivity. Indeed, pretreating NB4 PU.1knockdown cells with two different NF- $K$ B inhibitors $\mathrm{JSH}-23$ (blocks p65 nuclear translocation) or BAY 11-7085 (blocks $I_{\kappa} \mathrm{B} a$ phosphorylation) was found to partially restore TRAIL sensitivity of these cells (Figure 2c).

PU.1 binds to $\mathrm{p} 65$ and represses NF-кB activity. We next asked if PU.1 might directly interfere with the NF- $\kappa$ B pathway via p65. First, we observed co-precipitation of exogenously expressed PU.1 with FLAG-tagged p65 in H1299 cells. In addition, immunoprecipitation of exogenously expressed FLAG-tagged PU.1 co-precipitated endogenous p65 in the same cells (Figure 3a). Thus, our data indicate a new PU.1 and p65 protein-protein interaction. Further, to test if PU.1 and p65 interactions also occur at the endogenous level in AML cells, we used proximity ligation assay (PLA). A positive signal in PLA indicates that these two proteins are in close proximity $(<40 \mathrm{~nm})$ in situ. Indeed, endogenous PU.1 and p65 interact in two different AML cell lines (Figure 3b). These results suggest a novel PU.1-p65 protein interaction whereby PU.1 might directly regulate the prosurvival functions of the NF- $k \mathrm{~B}$ signaling pathway.

As we observed increased NF- $K B$ activity in PU.1-knockdown cells, and that PU. 1 and p65 interact, we investigated whether PU.1 represses NF- $k \mathrm{~B} / \mathrm{p} 65$ activity. To evaluate this possibility, PU.1-negative $\mathrm{H} 1299$ cells were co-transfected with increasing amounts of PU.1 and an NF- $k$ B luciferase reporter plasmid. In these cells, we observed a significant, dose-dependent decrease of NF- $\kappa \mathrm{B}$ reporter activity with increasing amounts of transfected PU.1 (Figure 3c, left panel). Next, we evaluated the inhibitory function of PU.1 on NF- $k B$ in regulating myeloid cell leukemia (MCL-1) transcription. PU.1 repressed an $M C L-1$ promoter reporter plasmid that contains NF- $K$ B-binding sites ${ }^{23}$ similar to the NF- $\kappa$ B luciferase reporter (Figure 3c, right panel). Thus, PU.1 represses NF- $k B$ signaling when PU.1 was exogenously expressed in PU.1-negative cell lines.

Antiapoptotic protein expression persists in TRAILtreated AML PU.1-knockdown cells. Because we observed decreased sensitivity to TRAIL paralleled by increased NF- $K B$ activity in PU.1-depleted cells, we next addressed whether antiapoptotic NF- $\mathrm{BB}$ targets were activated. Western blot analysis revealed that TRAIL treatment resulted in reduced expression of several antiapoptotic proteins including FLIP long $\left(\right.$ FLIP $\left.\mathrm{L}_{\mathrm{L}}\right)$, FLIP short $($ FLIPS $)$, XIAP, BCL-2 and MCL-1 in NB4, HL60 and MOLM-13 AML cells. In contrast, levels of antiapoptotic proteins upon TRAIL treatment persisted in PU.1-depleted cells in a cell line-dependent manner (Figure $4 \mathrm{a}$ and Supplementary Figures S5a and b). Moreover, a similar persistence of particular antiapoptotic mRNA was seen in NB4 and HL60 cells but not in MOLM-13 cells (Figures $4 b-d$ ). Of note, RIP1, a known caspase-8 substrate $^{24}$ that was cleaved in TRAIL-treated control cells was protected from cleavage in 
a

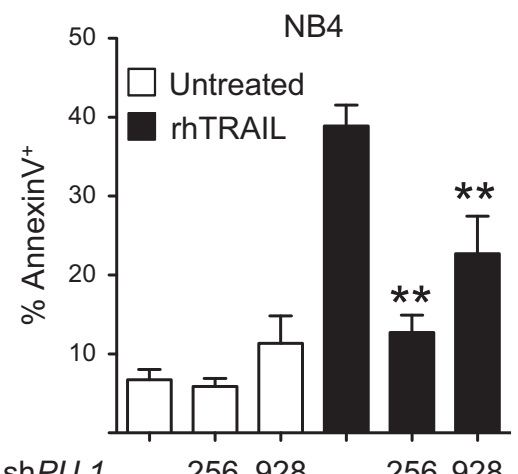

shPU.1 - 256928 - 256928

b

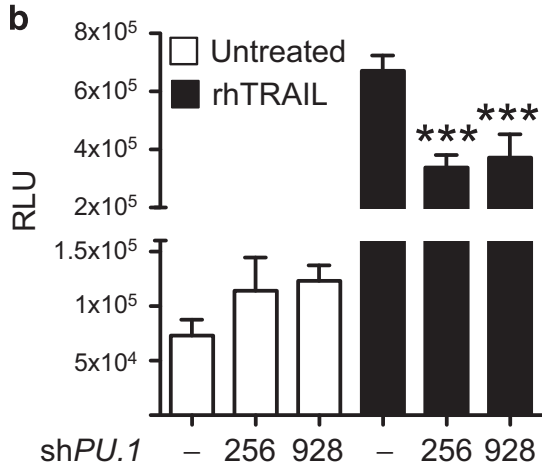

HL60

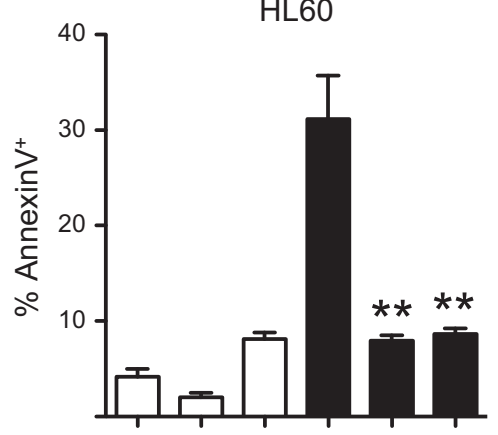

shPU.1 - 256928 - 256928

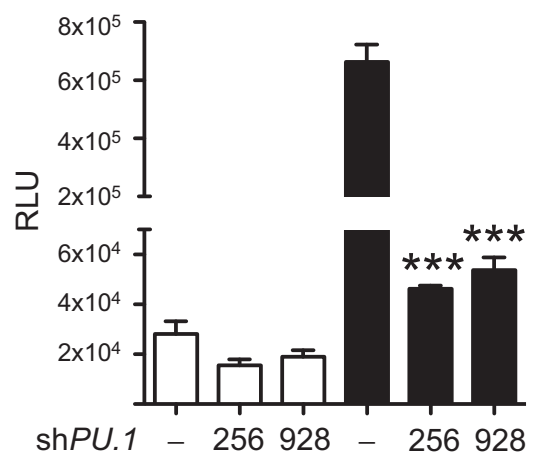

c

rhTRAIL $\quad-\quad+\quad+\quad+\quad+$ shPU.1 - $256928-256928$ kDa

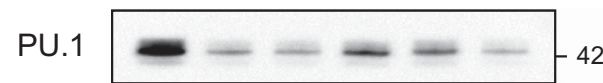

T. protein

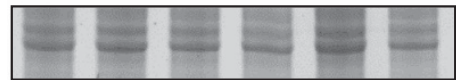

Pro-caspase-8
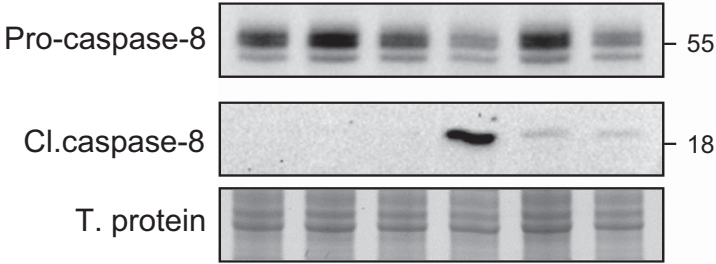

$\begin{aligned} & \text { Pro-caspase-3 } \\ & \text { (low exposure) }\end{aligned}--------{ }_{34}$
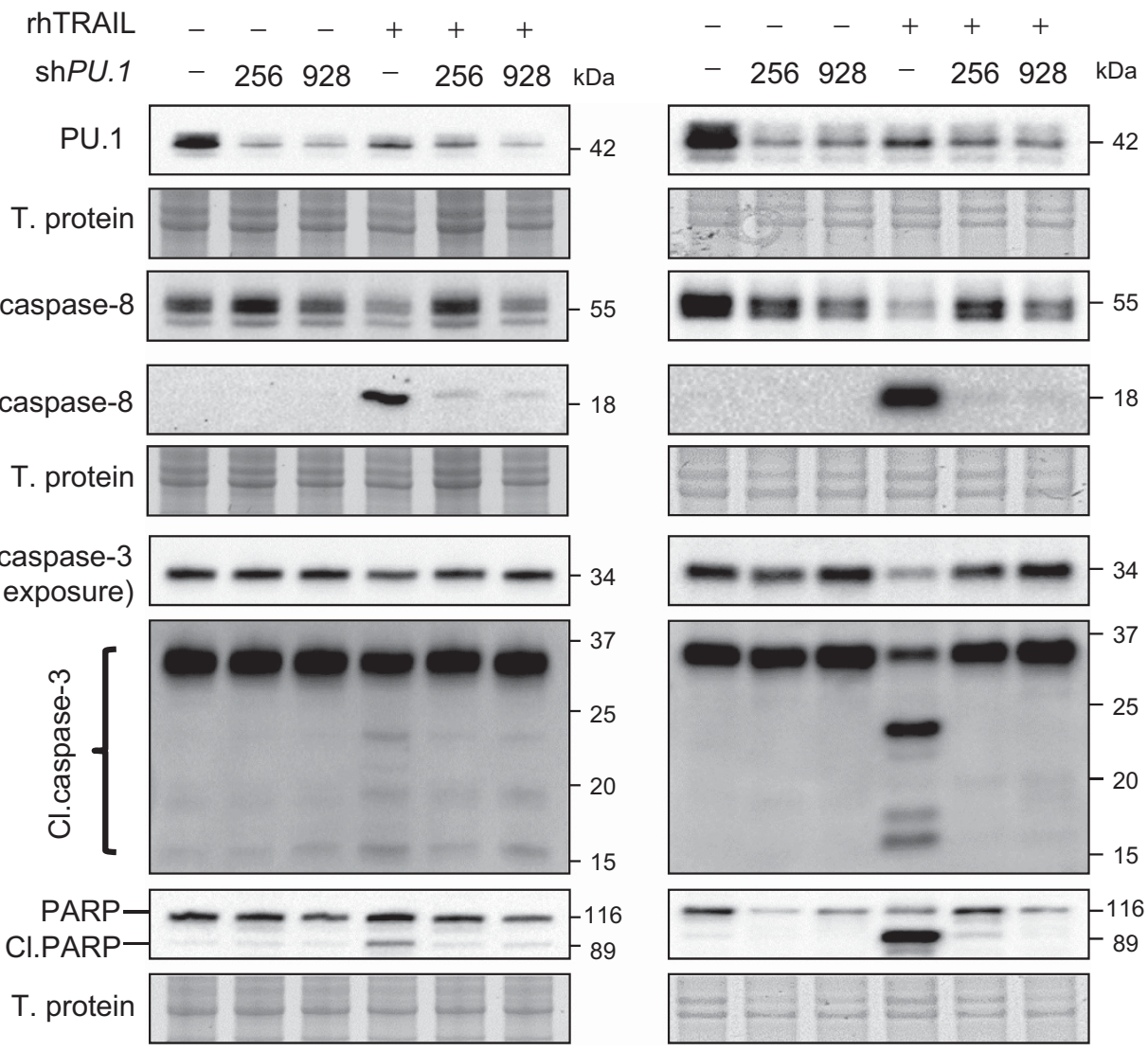
PU.1-depleted cells (Supplementary Figure S5c). Overall, these results suggest that the levels of several antiapoptotic proteins are less affected in TRAIL-treated PU.1-knockdown as opposed to AML control cells. Furthermore, increased levels of antiapoptotic genes likely contribute to the resistance mechanisms against TRAIL in PU.1-depleted cells.

TRAIL resistance in PU.1-depleted AML cells is associated with TRAIL receptor DR5 downregulation. As NF- $\kappa$ B pathway inhibition did not completely rescue the PU.1-knockdown phenotype and since resistance to TRAIL treatment is frequently associated with aberrant low expression of activating TRAIL receptors, we investigated if PU.1 levels are associated with TRAIL-activating receptor DR5 expression. As increased DR5 protein expression alone does not imply functional DR5 at the cell surface, we also determined DR5 surface expression by FACS analysis. First, we determined steady-state DR5 expression in all three AML cell lines used in this study. HL60 cells expressed the highest DR5 levels in accordance with being the most
TRAIL-sensitive cell line followed by MOLM-13 and NB4 cells (Supplementary Figure S6a). DcR2 mRNA levels showed a similar pattern as DR5, whereas DR4 and DcR1 levels did not parallel PU.1 expression (Supplementary Figure S6b). Furthermore, knocking down PU.1 resulted in a significant downregulation of DR5 surface, protein and mRNA expression in all three AML cells compared with control cells (Figures 5a-c). Significantly reduced expression of a second activating TRAIL receptor, DR4, was restricted to PU.1-depleted NB4 cells. Decoy receptor expression was reduced in NB4 cells as well but not in the other two cell lines (Supplementary Figures S6c-e). Focusing on activating TRAIL receptor expression upon TRAIL treatment, we found that markedly reduced DR5 and DR4 levels in PU.1-depleted NB4 and HL60 cells were paralleled by attenuated apoptosis (Figure $5 \mathrm{~d}$ and Supplementary Figures S7a and b).

The above results suggest that PU.1 regulates TRAIL receptor expression. Focusing on DR5, we found several putative PU.1- and p65-binding sites in the 5'-upstream DNA a

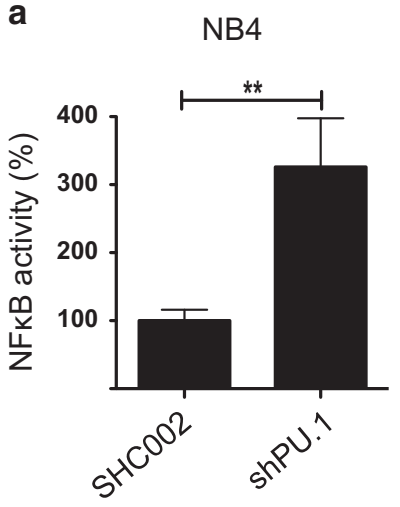

HL60

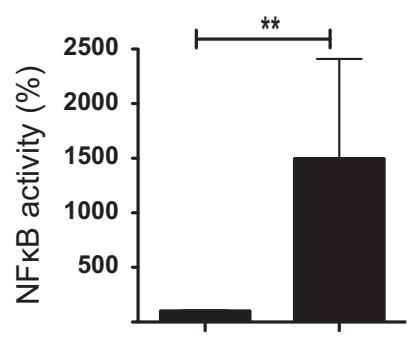

b

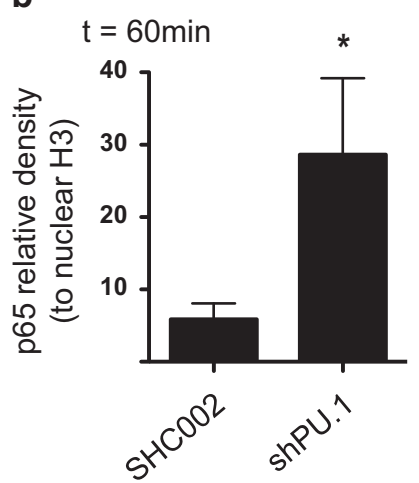

C

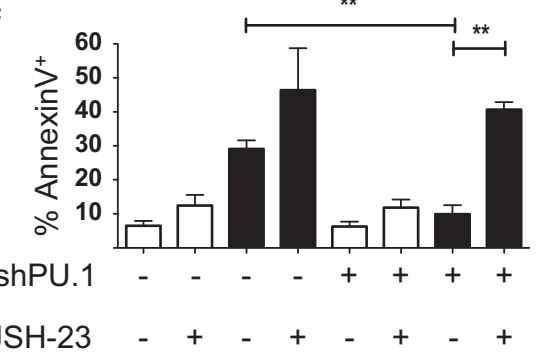

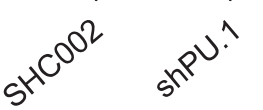

Untreated

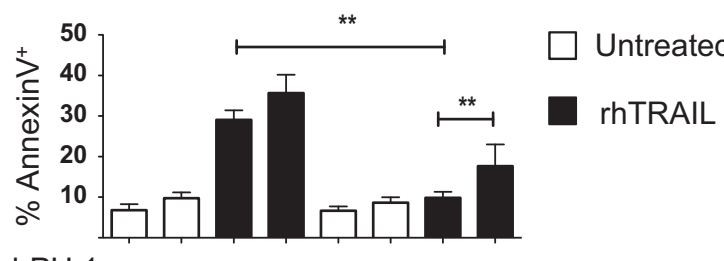

shPU.1 - $-\quad-\quad+\quad+\quad+$

JSH-23 - + + + + + + + BAY 11-7085 - + + + +

Figure 2 Inhibiting PU.1 increases nuclear factor- $\kappa$ B (NF- $\kappa$ B) activity in AML cells. (a) NB4 and HL60 control (SHC002) and PU.1-knockdown (shPU.1) cells were subjected to nucleofection with NF- $\kappa$ B Firefly luciferase reporter and Renilla luciferase expressing plasmids. Relative luciferase activity was determined by normalizing Firefly to Renilla luminescence. Results are given as the percentage of NF- $\kappa \mathrm{B}$ activity compared with control-transduced cells. (b) Total protein was fractioned into cytoplasmic and nuclear proteins. The amount of nuclear p65 after $1 \mathrm{~h}$ of TRAIL was quantified from three independent experiments using the Image Software and normalized to nuclear H3. (c) NB4 control and PU.1-knockdown cells were pre-treated for $8 \mathrm{~h}$ with 0.5 or $1 \mu \mathrm{M}$ of the NF- $\kappa$ B pathway inhibitors JSH-23 and BAY 11-7085, respectively, followed by $24 \mathrm{~h}$ of rhTRAIL $(500 \mathrm{ng} / \mathrm{ml})$ exposure. Percent of Annexin $\mathrm{V}^{+}$cells from three independent experiments are shown. ${ }^{\star \star} P<0.01 ;{ }^{*} P<0.05$

Figure 1 PU.1 depletion decreases sensitivity to TRAIL-induced apoptosis. (a) NB4 and HL60 AML cells stably expressing shRNA targeting PU.1 (shPU.1_256 and shPU.1_928) or a control shRNA (SHC002) were generated using lentiviral vectors. NB4 and HL60 cells were incubated with 500 and 50 ng/ml of recombinant human TRAlL (rhTRAIL) for 24 and $8 \mathrm{~h}$, respectively. Percent Annexin $\mathrm{V}^{+}$cells from three independent experiments are shown. (b) Control and PU.1 AML-knockdown cells were tested for caspase-3/7 activity. Relative luminescence (RLU) from three independent experiments is shown. ${ }^{* *} P<0.001 ;{ }^{* *} P<0.01$. (c) Western blotting for pro- and cleaved caspase-8, pro- and cleaved caspase-3, full-length and cleaved PARP as well as for PU.1 in control and PU.1-depleted NB4 and HL60 cells upon TRAIL treatment is shown. Total protein was used as a loading control. One out of two independent experiments is shown 
a

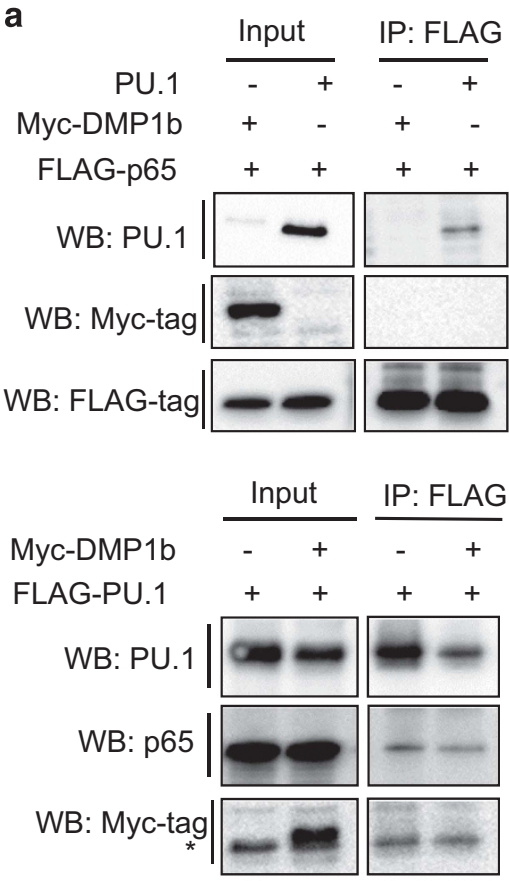

C

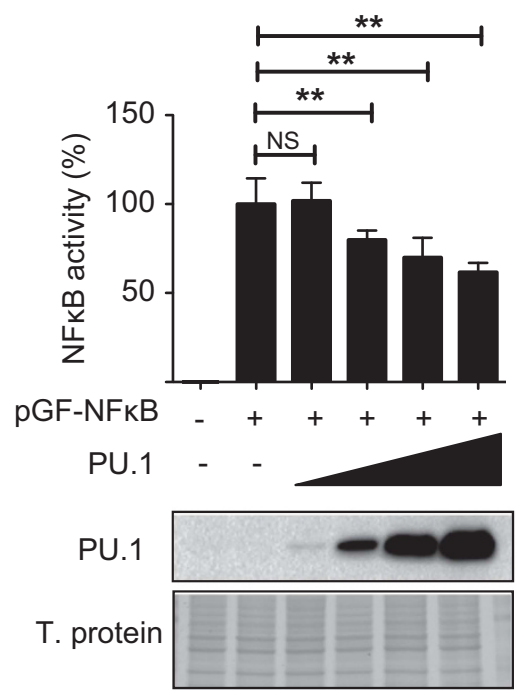

b

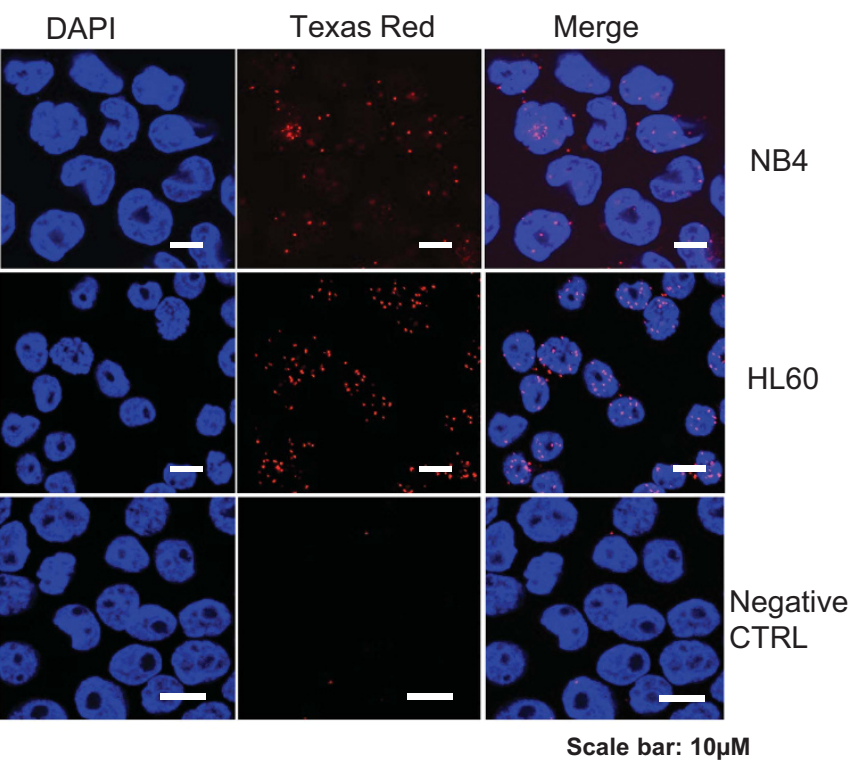

Figure 3 PU. 1 binds to $p 65$ and represses NF- $\kappa$ B activity. (a) H1299 cells were transfected with a FLAG-p65 expression plasmid and a PU.1 or an unrelated control plasmid expressing Myc-tagged DMP1 $\beta$. Anti-FLAG immunoprecipitation (IP) followed by immunoblotting with anti-FLAG, anti-PU.1 and anti-Myc-tag is shown. ("nonspecific band). In addition, to show binding of endogenous p65 to PU. $1 \mathrm{H} 1299$ cells were transfected with FLAG-tagged PU. 1 or an unrelated Myc-tagged DMP1 $\beta$ control plasmid. Cell lysates were subjected to anti-FLAG IP followed by immunoblotting with anti-PU.1, anti-Myc and anti-p65. (b) PLA to analyze endogenous PU.1 and p65 interaction in NB4 and HL60 cells. Cells were fixed with 4\% paraformaldehyde (PFA) and stained for endogenous PU.1 and p65 using anti-PU.1 and anti-p65 antibody. Interaction of endogenous PU.1 and p65 was detected using confocal microscopy. A red fluorescent dot indicated that these two proteins are in close proximity $(<40 \mathrm{~nm})$. The negative control represents cells incubated without primary antibodies. Scale bar, $10 \mu \mathrm{M}$. (c) H1299 cells were transfected with a pGL4-NF-kB (left panel) or a pGL2-Mcl-1 luciferase (right panel) reporter and various amounts of a wild-type PU.1 expressing plasmid. The amount of transfected plasmid between the different transfections was adjusted using empty vector. Cells were analyzed as in Figure 2a. Cells lysates were assayed by immunoblotting for PU.1 expression using anti-PU.1 antibody. Results from at least three independent experiments are shown

region of the DR5 gene (Supplementary Figure S7c). PU.1 and p65 chromatin immunoprecipitation (ChIP) confirmed binding of both transcription factors to a DNA region with neighboring PU.1- and p65-binding sites (Figure 5e). Using an inducible PU.1-estrogen receptor fusion protein (PU.1-ER) to specifically induce PU. 1 target genes, ${ }^{25}$ we found a significant, 3-4-fold increase in DR5 mRNA expression paralleled by a marked increase in DR5 protein expression after 4-hydroxytamoxifen stimulation (Figure $5 f$ and Supplementary Figure S7d). Importantly, activation of PU.1 did not induce DR4 transcription, whereas G-CSF-R mRNA, a known PU.1 target, ${ }^{26}$ was significantly induced (Supplementary Figures S7e and f). Overall, DR5 transcription is directly activated by PU.1 and knocking down PU.1 resulted in reduced DR5 
a

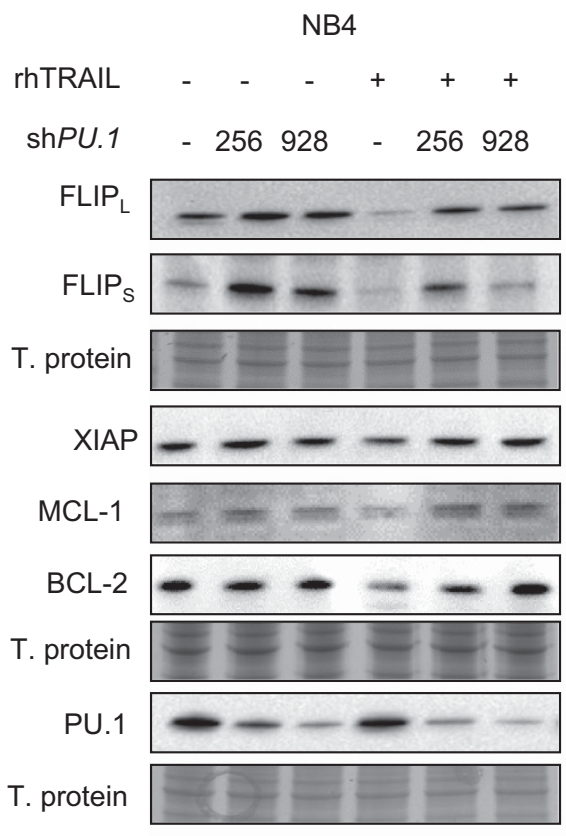

HL60

- $256928-256928$
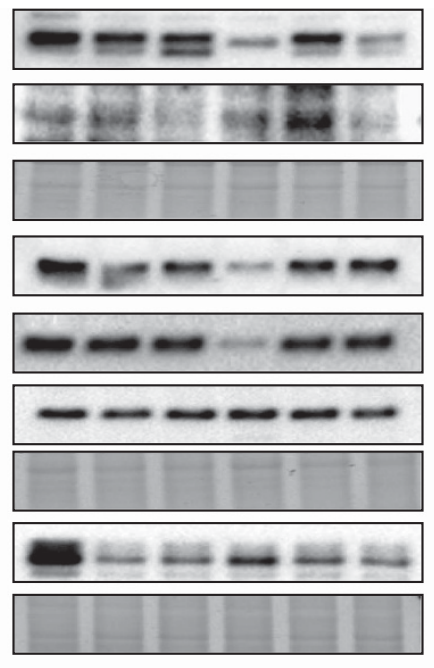

MOLM-13

b

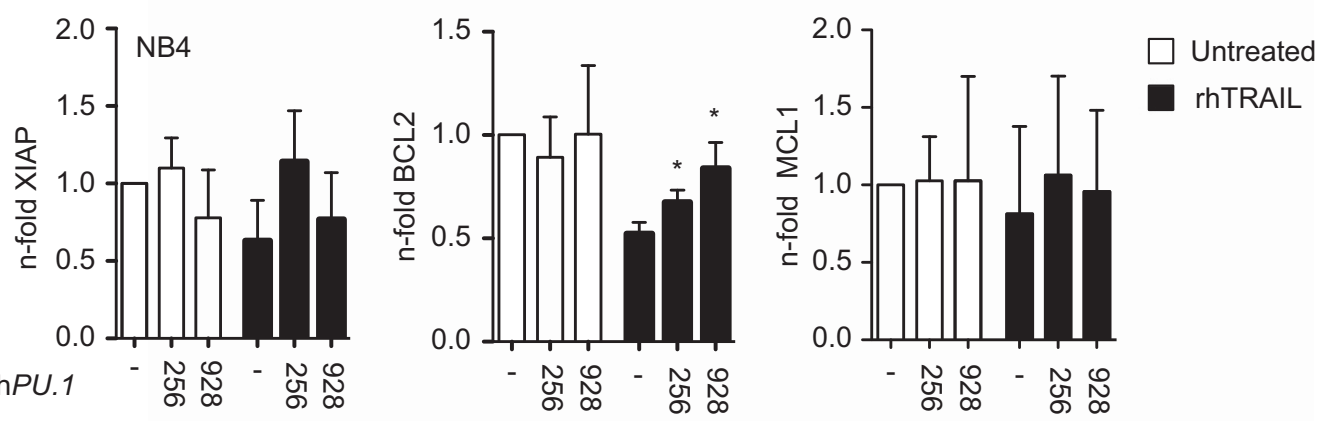

C

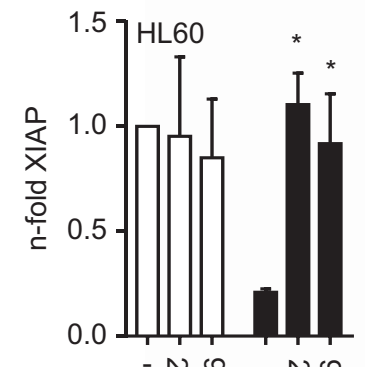
shPU.1

ज్ N
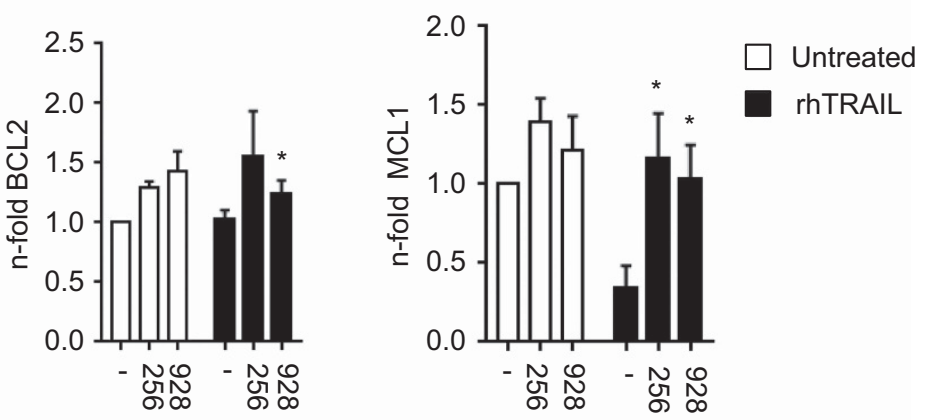

d
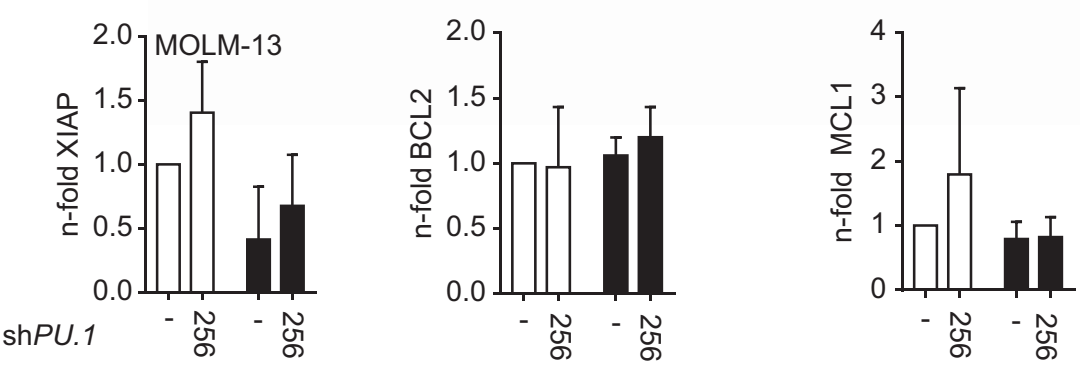

Figure 4 Persistent expression of particular antiapoptotic proteins in TRAIL-treated PU.1-depleted AML cells. (a) XIAP, FLIP (FLIPL and FLIPS), BCL-2, MCL-1 and PU.1 western blot analysis of control and PU.1-depleted NB4, HL60 and MOLM-13 AML cells. Total protein was used as a loading control. One out of two independent experiments is shown. (b-d) XIAP, BCL-2 and MCL-1 quantitative RT-PCR (qPCR) analysis of NB4, HL60 and MOLM-13 cells treated as in (a). ${ }^{*} P<0.05$ 
expression in all three AML cell lines investigated likely contributing to the observed decreased sensitivity to TRAIL. As depleting PU.1 only resulted in reduced DR4 mRNA levels in untreated NB4 cells and DR4 transcription was not induced by PU.1 activation in two AML cell lines, we speculate that DR4 is not a direct transcriptional target of PU.1.

Given that PU.1 knockdown causes partial resistance to TRAIL and that inducing PU.1 resulted in increased DR5 surface expression, we next evaluated whether inducing PU.1 would sensitize AML cells to TRAIL-induced cell death. Indeed, activation of PU.1 resulted in a significantly higher percentage of Annexin $\mathrm{V}^{+}$cells upon TRAIL treatment (Figure 5g). Importantly, induction of PU.1 alone without TRAIL treatment already resulted in increased cell death as evidenced by increased Annexin $\mathrm{V}$ staining and increased levels of cleaved PARP (Figure 5h, upper panels). In addition, activation of PU.1 upon TRAIL treatment attenuated the expression of FLIPS, BCL-2 and MCL-1, all proteins whose expression increases upon PU.1 depletion (Figure 5h, lower panels). Interestingly, PU.1 expression resulted in a shift toward the expression of FLIP $\mathrm{L}$. These results suggest that PU.1 exerts a proapoptotic role by upregulating DR5 and causing lower expression of several antiapoptotic proteins.

PU.1 depletion protects from anthracycline-mediated apoptosis. Current AML therapy does not include TRAIL, but is based on the use of the anthracyclines. ${ }^{27}$ Thus, we asked whether the absence of PU.1 attenuated intrinsic apoptotic pathways as well. We incubated wild-type and PU.1-depleted AML cells with the anthracyclines doxorubicin or idarubicin, and then assessed cell viability by Annexin V staining and caspase-3/7 activity. Similar to TRAIL treatment, knocking down PU.1 resulted in a significant apoptosis inhibition as compared with wild-type cells treated with either doxorubicin or idarubicin, which was supported by a marked decrease in caspase-3 and PARP cleavage (Figure 6a). Most importantly, as with TRAIL treatment of PU.1-depleted cells, treatment with both anthracyclines resulted in persistent expression of the antiapoptotic proteins XIAP, BCL-2 and MCL-1 (Figure 6b). Importantly, blocking Bcl-2 with the BCL-2-selective inhibitor ABT-199 restored sensitivity to anthracyclines underlining the relevance of $\mathrm{Bcl}-2$ in resistance mechanisms towards chemotherapeutics in PU.1- depleted AML cells (Figure 6c). In conclusion, PU.1 supports anthracycline-mediated cell death in AML cells.

\section{Discussion}

The key finding of this study is the novel function of PU.1 in cell death responses to clinically relevant drugs in $A M L$ cells. Mechanistically, PU.1 significantly prevents NF- $\kappa$ B-mediated upregulation of antiapoptotic genes such as $C F L I P, M C L-1$, $B C L-2$ and $B C L-X L$ upon TRAIL treatment. We showed for the first time that PU.1 directly binds to RelA/p65 and thereby represses the transcriptional activity of $p 65$. In addition, PU.1 contributes to TRAIL sensitivity by directly inducing TRAIL receptor DR5 transcription. Overall, our findings further expand the function of the PU.1 transcription factor to cell death responses towards anticancer therapies.

The effects of PU.1 and NF- $\kappa \mathrm{B}$ are tightly linked as they interdependently regulate gene transcription by binding to the same promoter regions of common target genes. The combined actions of these two transcription factors might have synergistic activating or inhibiting functions. Moreover, NF- $k B$ directly regulates PU. 1 at the transcriptional level by binding to the $5^{\prime}$-URE of the PU.1 gene. ${ }^{28}$ PU. 1 affects, together with $\mathrm{C} / \mathrm{EBP} a, \mathrm{NF}-\kappa \mathrm{B}$ target selection in THP-1 cells by mediating the formation of active protein complexes at the enhancer region of target genes. ${ }^{29}$ In addition, the NF- $k$ B1/p50 promoter is directly regulated by PU.1 and transcriptional family member, Spi-B. ${ }^{30}$ Given that another myeloid transcription factor, C/EBPa, interacts with the NF- $k \mathrm{~B}$ pathway proteins to induce expression of the antiapoptotic BCL-2 in AML, ${ }^{31}$ we asked whether PU.1 also directly interacts with this survival pathway. We were able to co-precipitate endogenous RelA/p65 with FLAG-tagged PU.1 expressed in $\mathrm{H} 1299$ cells. The direct interaction of endogenous RelA/p65 and PU.1 was shown by an in situ PLA. In contrast to our findings, Shen and Stavnezer ${ }^{32}$ used PU.1 as a specificity control for their GST-pull-down assay to show p65 and STAT6 interaction. GST-p65 did not pull down PU.1 from $1.29 \mu$ B-lymphoma cell nuclear extracts. This discrepancy may be due to the use of more sensitive in vitro assays or may reflect differences in B-lymphoma versus AML cells.

Using an NF- $\kappa \mathrm{B}$ reporter consisting of a concatemer of NF$\kappa \mathrm{B}$-binding motifs and an MCL-1 promoter reporter with an NF$\kappa \mathrm{B}$-binding site, we found that PU.1 negatively impacts on NF-

\footnotetext{
Figure 5 PU.1 positively regulates DR5 expression and sensitizes AML cells to apoptosis. (a-c) Flow cytometry analysis of DR5 surface expression, DR5 and PU.1 western blot and quantitative RT-PCR (qPCR) analysis in NB4, HL60 as well as MOLM-13 control and PU.1-knockdown cells. Total protein was used as a loading control for western blot data. qPCR values were normalized to the housekeeping gene HMBS. Results are given as $n$-fold changes compared with control cells. (d) DR5 qPCR, DR5, cleaved PARP as well as PU.1 western blot and DR5 FACS analysis of NB4 control and PU.1-knockdown cells upon TRAIL treatment. Analysis as in (a). One out of three independent experiments is shown. (e) PU.1 and p65 ChIP analysis of three putative, neighboring PU.1/p65-binding sites upstream of the transcriptional start site of the DR5 gene. In vivo binding of PU.1 and p65 to the indicated sites was shown by ChIP in NB4 cells using antibodies against PU.1 and p65. Antibodies against acetyl-histone H3 and lgG were used as a positive and negative control, respectively. GAPDH amplification was shown as a negative control for the different pulldowns. (f) DR5 expression analysis of NB4 cells expressing an inducible PU.1-estrogen receptor (PU.1-ER) fusion protein. DR5 qPCR, western blot and FACS analysis of NB4 control and PU.1-knockdown cells 48 h after 4-hydroxy-tamoxifen (4-OH-T) stimulation from three independent experiments. (g) Viability of NB4 control and PU.1-ER-expressing cells upon PU.1 activation for $48 \mathrm{~h}$ with $4-\mathrm{OH}-\mathrm{T}$ stimulation. Cells were incubated with rhTRAIL $(500 \mathrm{ng} / \mathrm{ml}) 24 \mathrm{~h}$ after 4-OH-T addition. Percent of Annexin $\mathrm{V}^{+}$cells from three independent experiments are shown (upper panel) and immunoblotting for pro- and cleaved caspase-8, cleaved caspase-3 and cleaved PARP are shown (lower panel). Total protein was used as a loading control. (h) Viability of NB4 control and PU.1-ERexpressing cells treated as in (f). Percent of Annexin $\mathrm{V}^{+}$cells from three independent experiments are shown. Immunoblotting for cleaved PARP, FLIP $\mathrm{L}$ and FLIPS, BCl-2 and Mcl-1 is shown. Analysis as in (g). ${ }^{* *} P<0.01 ;{ }^{*} P<0.05$
} 
$\kappa \mathrm{B}$ 's capacity to activate transcription. Furthermore, NF- $\kappa \mathrm{B}$ promotes cell survival through the activation of several antiapoptotic genes including $F L I P,{ }^{33} M C l-1^{34}$ or XIAP. ${ }^{35}$
Consistently, we showed that increased expression of NF- $\kappa$ Bregulated antiapoptotic genes in PU.1-depleted AML cells that contributed to the resistance phenotype against TRAIL. The

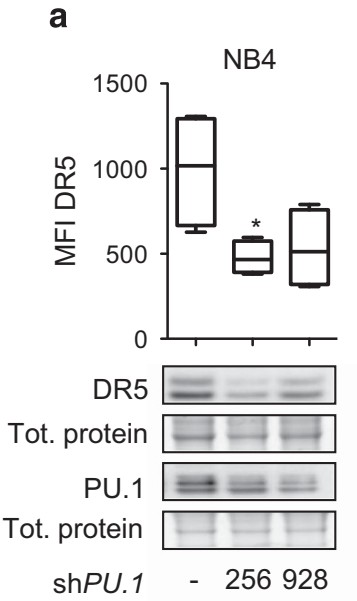

c

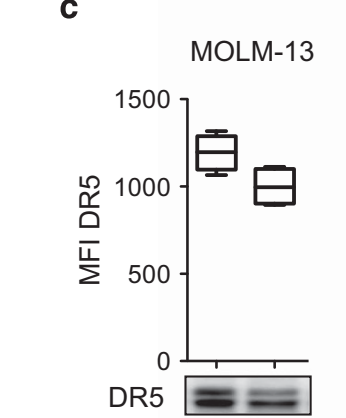

Tot. protein $\square$

PU.1

Tot. protein

shPU.1

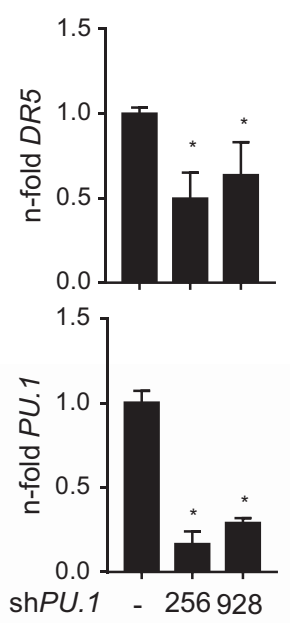

b

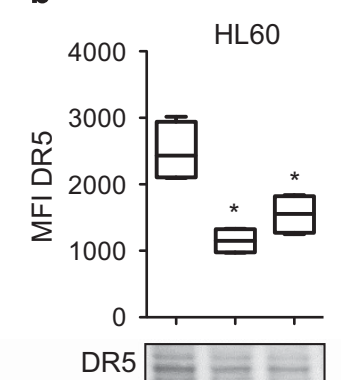

Tot. protein

PU.1

Tot. protein

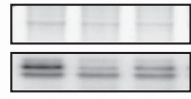

shPU.1 - 256928

d

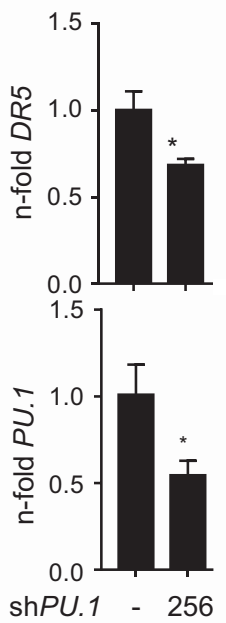

e

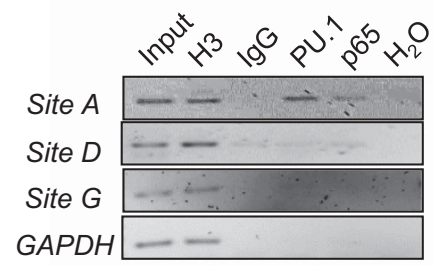

f

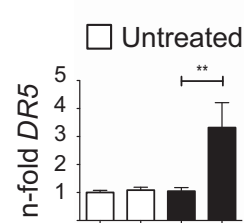

T. Protein

DR5 $-\cdots$

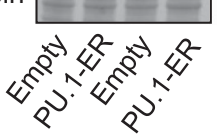

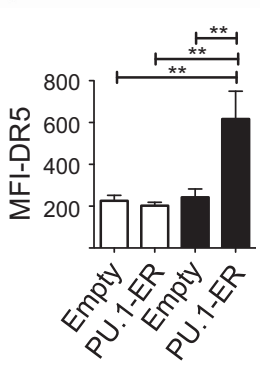

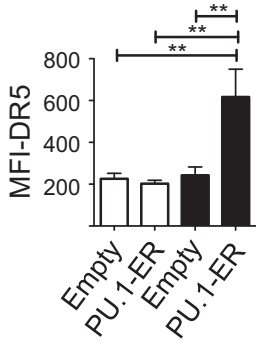

4-OH-T

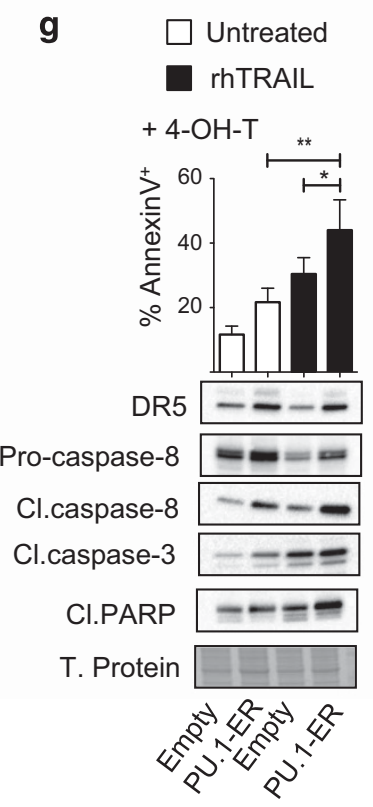

h $\square$ Untreated 4-OH-T

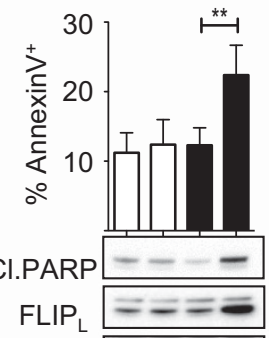

FLIP $_{\mathrm{S}}-1-$

T. Protein

$\mathrm{Bcl}-2$

Mcl-1

T. Protein

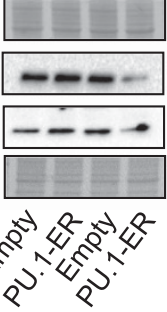


resistance seen in PU.1-depleted AML cells can partially be overcome by using NF- $\kappa \mathrm{B}$ inhibitors in combination with TRAIL. Furthermore, using a tamoxifen-inducible PU.1 overexpression system, we found that activation of PU.1-sensitized NB4 cells to TRAIL. Of note, activation of PU.1 per se did induce significant cell death possibly by activating endogenous TRAIL (Figure $5 \mathrm{~g}$ ). In agreement with our data, Tatetsu et al. ${ }^{36}$ observed a similar effect in U266 myeloma cells using a tetracycline-inducible PU.1 overexpression system. Induction of PU.1 resulted in increased cell death of U266 cells paralleled by decreased expression of antiapoptotic Bcl-XL and $B C L-2 A 1$ proteins as well as increased levels of cleaved caspase-3.

It is rather intriguing that PU.1 directly or indirectly activates pro- or antiapoptotic factors depending on the cell type and cellular context. For example, on the one hand, PU.1 attenuates Bim transcription, which in turn promotes apoptosis resistance in leukemia, ${ }^{7}$ and on the other hand, PU. 1 directly activates TRAIL transcription leading to cell death in myeloma cells. ${ }^{37}$ Here, we provide evidence that PU. 1 transcriptionally regulates the TRAIL receptor DR5 leading to a significant increase in DR5 surface expression and increased TRAIL sensitivity. This direct activation of the DR5 adds this gene to the list of proapoptotic genes under the control of PU.1. Alternatively, persistent expression of decoy receptor DcR2 (TRAIL-4) or decreased expression of DR4 as found in PU.1depleted NB4 cells upon TRAIL treatment may contribute to the decreased TRAIL responsiveness in particular cell types (Supplementary Figures S6d and S8a).

PU.1 also interacts with and attenuates transcriptional activity of the proapoptotic p53 tumor suppressor, ${ }^{38}$ a feature that might contribute to erythroleukemia development where untimely expression of PU.1 leads to a failure in erythroid differentiation. In this study, depleting PU.1 rendered p53 wildtype (MOLM-13), p53 mutant (NB4) as well as p53-null (HL60) AML cells less sensitive toward TRAIL treatment. This indicates that p53-independent mechanisms contribute to PU.1-mediated cell death responses to TRAIL as well as to anthracycline treatment. An earlier report from our group described the antiapoptotic BCL-2A1 as a direct transcriptional target of PU.1 that contributes to the survival of granulocytes during all-trans-retinoic acid (ATRA)-induced neutrophil differentiation of APL cells. ${ }^{8}$ Accordingly, specifically knocking down Bcl2a1a and not $B c / 2 a 1 b / d$ in the murine hematopoietic system resulted in increased spontaneous cell death in granulocytes. ${ }^{39}$ Thus, we suggest a rather specific role for BCL-2A1 in hematopoietic cell survival upon terminal differentiation. Nevertheless, BCL-2A1 is a direct transcriptional target of NF- $\kappa \mathrm{B}$ and can substitute for NF- $\kappa \mathrm{B}$ to suppress TNFa-induced apoptosis, and we cannot exclude that it is involved in modulating PU.1-controlled cell survival upon TRAIL treatment. ${ }^{40}$ Overall, we propose that cellular context regulates PU.1 function in balancing the expression of prosurvival and antiapoptotic genes.

Importantly, decreased sensitivity of PU.1-knockdown cells was not only observed during TRAIL but also during conventional chemotherapy treatment (idarubicin, doxorubicin) of AML cells. Similar to TRAIL treatment, we observed persistent expression of the antiapoptotic proteins XIAP, BCL-2 and MCL-1 in PU.1-depleted cells (Figure 6). These data are supported by earlier data from Zhao et al. ${ }^{41}$ showing that knocking down PU.1 in U937 AML cells allowed for BCL-2 expression upon etoposide treatment. The resistance against different death stimuli in PU.1-depleted cells strongly suggests a more general function of PU.1 in regulating not only extrinsic but also intrinsic apoptosis as engaged by DNA-damaging agents.

In this study, we investigated the role of PU.1 in cell death mediated by anticancer therapies and found that PU.1 exerts proapoptotic functions by repressing the prosurvival function of NF-KB and by increasing death receptor DR5 expression. The overall outcome on cell death upon PU. 1 depletion in all $\mathrm{AML}$ cell lines investigated is similar, but we speculate that the three cell lines differ to which extent they engage PU.1-dependent NF- $k$ B inhibition or DR5 upregulation to increase TRAIL sensitivity (Supplementary Figure $S 8 b$ ). Reactivation of PU. 1 in AML cells may represent an interesting strategy for sensitizing these cells to current cytotoxic therapies. Since ATRA can restore PU.1 expression in APL cells and can also induce TRAIL expression, and combination therapies with TRAIL and ATRA might be of interest. ${ }^{5,42}$ Alternatively, the use of NF- $k B$ inhibitors in combination with TRAIL may represent an intriguing treatment option. These inhibitors are currently not used in the clinics due to their strong side effects. ${ }^{43}$ Nevertheless, NF- $k$ B inhibitors might still be a valuable option when used at lower doses and in combination with other drugs during a short therapeutic window. Taken together, our findings may provide useful information for the development of alternative therapeutic strategies in AML by modulating the PU.1 pathway.

\begin{abstract}
Materials and Methods
Cell lines and culture conditions. The human AML NB4, HL60 and MOLM-13 as well as the B-ALL REH and the non-small-cell lung cancer H1299 cell lines were maintained in RPMI-1640 (Sigma-Aldrich, Switzerland) supplemented with 10\% FBS (no. S0615; Biochrom GmbH, Germany) and 1\% penicillin/ streptomycin (P4333; Sigma-Aldrich). Cells were cultured in a humidified atmosphere containing $5 \% \quad \mathrm{CO}_{2}$ at $37^{\circ} \mathrm{C}$. The human embryonic kidney 293T cells were cultured in DMEM (Sigma-Aldrich) supplemented with 5\% FBS, $1 \%$ penicillin/streptomycin and $1 \%$ HEPES (Sigma-Aldrich), and kept in a humidified atmosphere containing $7.5 \% \mathrm{CO}_{2}$ at $37^{\circ} \mathrm{C}$.
\end{abstract}

Transient transfections and reporter assays. $\mathrm{H} 1299$ cells were transiently transfected with pGL4-NF $\kappa B$ (Promega AG, Switzerland) or pGL2-Mcl1 (Addgene plasmid no. 19132) Firefly luciferase reporter plasmid using Lipofectamine (Invitrogen, Switzerland). NB4 and HL60 cells were transiently transfected with pGL4-NFKB (Promega) using nucleofection (no. VCA-1003; Lonza Group Ltd, Switzerland). Cells were lysed for $24 \mathrm{~h}$ (Lipofectamine) or $5 \mathrm{~h}$ (Nucleofection) after transfection and assayed for luciferase activity using the DualGlo Luciferase Assay Kit (Promega). Firefly luciferase activity was normalized to that of Renilla luciferase expressed from the co-transfected PGL-Renilla plasmid. Results, expressed as ratio of Firefly to Renilla luciferase (relative luciferase activity), are the means of three independent experiments measured in triplicate. Error bars represent standard deviations.

Generation of PU.1-knockdown and PU.1-ER-expressing cell lines. pLKO.1 lentiviral vectors expressing shRNAs targeting PU.1 (shPU.1_256: NM_003120.1-256s1c1/TRCN0000020536 and shPU.1_928: NM_003120.1928s1c1/TRCN0000020538), or a nontargeting shRNA control (SHCOO2) were purchased from Sigma-Aldrich and have been validated earlier. ${ }^{11,44,45}$ The retroviral pBabe-PUER-puro vector (kindly provided by Dr. H Yoshida) was co-transfected with the $\mathrm{pCl} 10 \mathrm{~A} 1$ packaging construct to generate recombinant retrovirus. Lentiviral and retroviral transductions were carried out as described. ${ }^{44,46}$ All vectors contain a 
a
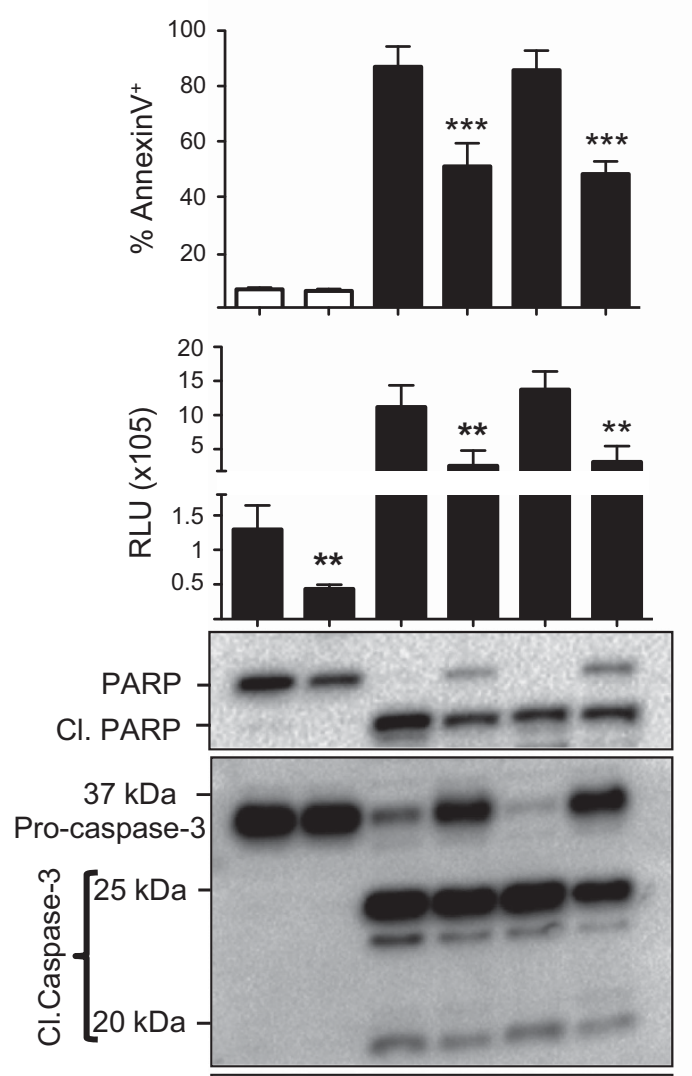

T. protein

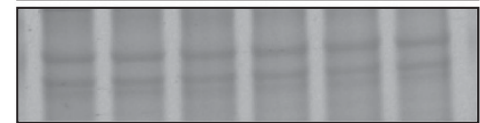

PU.1

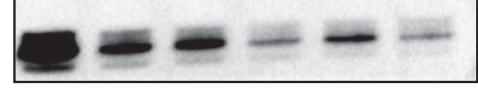

T. protein

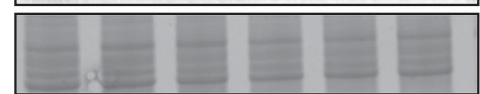

$\operatorname{sh} P U .1$

Idarubicin

Doxorubicin b
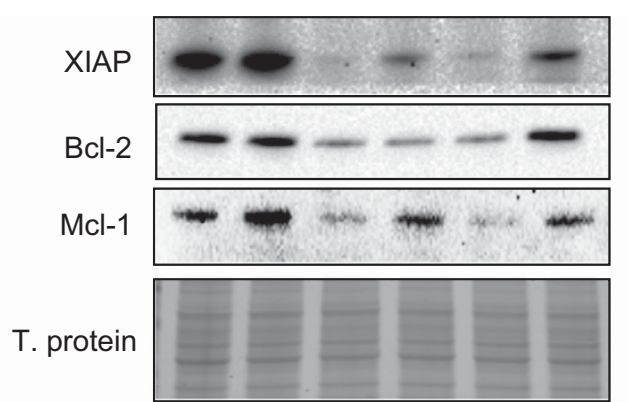

$\operatorname{sh} P U .1$ Idarubicin

Doxorubicin

C

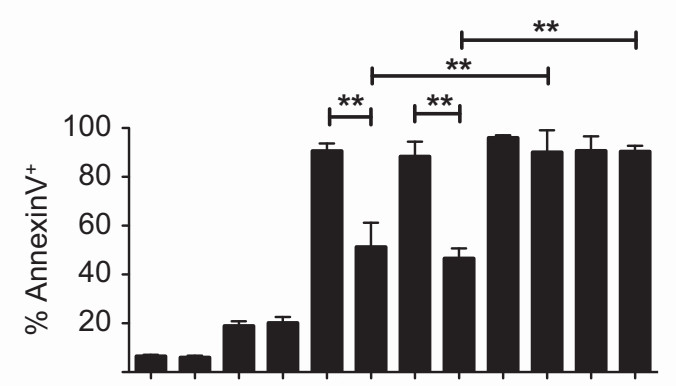

CI. PARP

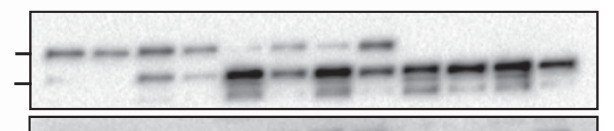

$37 \mathrm{kDa}$

Pro-caspase-3

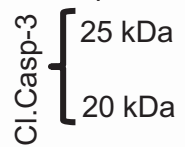

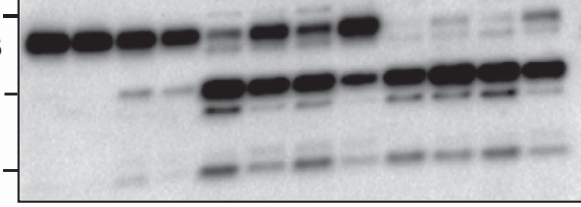

T. protein

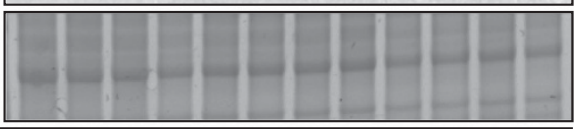

PU.1

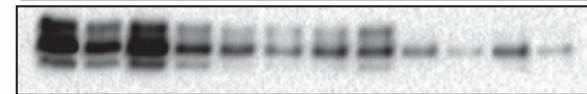

T. protein

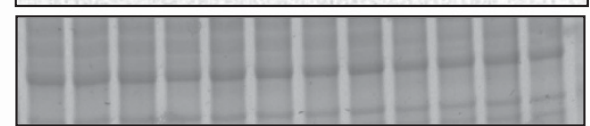

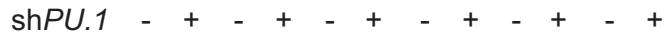

Idarubicin - $-C_{-}++_{-}-++{ }_{-}-$

Doxorubicin - $-\quad-\quad-\quad-\quad+\quad+\quad-\quad+\quad$

ABT-199 - $\quad+\quad+\quad-\quad-\quad-++++$

Figure 6 PU.1 depletion decreases sensitivity to anthracycline-mediated apoptosis in AML cells. (a) NB4 control and PU.1-knockdown cells were incubated for $48 \mathrm{~h}$ with 0.01 or $0.1 \mu \mathrm{M}$ of idarubicin and doxorubicin, respectively. Upper panel: Cells were analyzed by flow cytometry for Annexin V/propidium iodide staining and tested for caspase-3/7 activity. Percent of Annexin $\mathrm{V}^{+}$cells and relative luminescence (RLU) from three independent experiments are shown. Lower panel: Caspase-3, cleaved caspase-3, PARP, cleaved PARP and PU.1 western blotting is shown. One out of three independent experiments is shown. ${ }^{* *} P<0.01$. (b) NB4 control and PU.1-knockdown cells treated as in (a) were subjected to immunoblotting with anti-Bcl-2, anti-XIAP and anti-Mcl-1. Total protein was used as a loading control. One out of three independent experiments is shown. (c) NB4 control and PU.1-knockdown cells were preincubated with $1 \mu \mathrm{M}$ of ABT-199 for $1 \mathrm{~h}$ before $48 \mathrm{~h}$ incubation with 0.01 or $0.1 \mu \mathrm{M}$ of idarubicin and doxorubicin, respectively. Upper panel: Cells were analyzed by flow cytometry for Annexin V/propidium iodide staining. Lower panel: Pro- and cleaved caspase-3, full-length PARP, cleaved PARP and PU.1 western blotting is shown. Total protein was used as a loading control. One out of two independent experiments is shown. ${ }^{* \star} P<0.001 ;{ }^{* \star} P<0.01$

puromycin antibiotic resistance gene for selection of transduced mammalian cells. Transduced cells were selected for 4 days using $1.5 \mu \mathrm{g} / \mathrm{ml}$ puromycin.

Antibodies and immunoblotting. The primary antibodies used were antiPU.1 (no. 2258; Cell Signaling, Switzerland or sc-365208; Santa Cruz, Switzerland),
anti-cFLIP (F9800; Sigma) and (AG-20B-0056; Adipogen AG, Switzerland), antiXIAP (M044-3; MBL, Switzerland), anti-caspase-3 (235412; Calbiochem, Switzerland) and (no. 9661; Cell Signaling), anti-PARP (nos 9542, 9541; Cell Signaling) anti-cleaved caspase-8 (no. 9496; Cell Signaling), anti-caspase-8 (ALX-804-242; Enzo Life Sciences (ELS) AG, Switzerland), anti-Bcl-2 
(SAB4500003; Sigma), anti-Mcl-1 (559027; BD Biosciences, Switzerland), anti-DR5 (no. 8074; Cell Signaling), anti-DcR2 (no. 8049; Cell Signaling), anti-p65 (no. 8242; Cell Signaling), anti-phospho-p65 (no. 3033; Cell Signaling), anti-IкB $\alpha$ (no. 4814; Cell Signaling) anti-phospho-IKB $\alpha$ (no. 2859; Cell Signaling), anti-RIPK1 (no. 3493; Cell Signaling) anti- $\alpha$-tubulin (no. 3873; Cell Signaling, anti-Myc tag (ab13836; Abcam), anti-FLAG tag (no. 2368; Cell Signaling)) and anti-histone H3 (no. 9715; Cell Signaling). Secondary antibodies used were anti-mouse IgG HRP- and antirabbit IgG HRP-linked (nos 7076, 7074; Cell Signaling) and (NA93IV; GE Healthcare Europe $\mathrm{GmbH}$, Switzerland).

For immunoblotting, cells were lysed in urea buffer $\left(40 \mu / / 5 \times 10^{6}\right.$ cells) consisting of $8 \mathrm{M}$ urea and $0.5 \%$ (v/v) Triton X-100 supplemented with Protease Inhibitor Cocktail (Roche Diagnostics (Schweiz) AG, Switzerland). The lysates were briefly sonicated and then centrifuged at $13 \times 10^{5} \times g$ for $15 \mathrm{~min}$ in a refrigerated microcentrifuge. Protein content was determined using a Bradford Assay (no. 500-0006; Bio-Rad Laboratories AG, Switzerland). Thirty micrograms of total protein was analyzed by electrophoresis on a mini-protean TGX Stain-Free Precast Gel (Bio-Rad). Immunocomplexes were visualized by chemiluminescence using an ECL Kit (BioRad Laboratories AG, Switzerland). Data were acquired using the ChemiDoc MP System (Bio-Rad). For reliable quantification of our immunoblotting results, genespecific protein expression was normalized to total protein expression and not to commonly used loading controls such such as GAPDH or $\beta$-actin. ${ }^{47,48}$

Immunoprecipitation and cellular fractionation. FLAG-immunoprecipitations were performed using the FLAG Immunoprecipitation Kit (Sigma) according to the manufacturer's instructions. Immunoblotting was performed as described above. Cytoplasmatic and nuclear fractionation was achieved by first lysing the cells in buffer A (HEPES $10 \mathrm{mM}(\mathrm{pH} 8.0), \mathrm{KCl} 10 \mathrm{mM}, \mathrm{MgCl}_{2} 1.5 \mathrm{mM}$, DTT $1 \mathrm{mM}$ ), centrifugation and recovering the supernatant. The cell pellet was resuspended in buffer B (HEPES $20 \mathrm{mM}$ (pH 8.0), $\mathrm{MgCl}_{2} 1.5 \mathrm{mM}, \mathrm{KCl} 400 \mathrm{mM}$, $\mathrm{NaCl} 40 \mathrm{mM}$, EDTA $0.2 \mathrm{mM}$, DTT $1 \mathrm{mM}$, glycerol $25 \%$ ) to lyse the nuclear envelope and nuclear proteins were extracted. Five micrograms of cytoplasmic and nuclear protein was analyzed by western blotting as described above.

Chromatin immunoprecipitation. ChIP assays were carried out according to the protocol provided by Active Motif (La Hulpe, Belgium). Following DNA purification, PCR was performed using a JumpStart Taq (Sigma) and the following primers: DR5 promoter site 1 - forward, 5'-GTAATTCCAGTACCGTG-3' and reverse, 5'-TGGGACTAGGTGCAC-3'; DR5 promoter site 2 - forward, 5'-GTAAA GGTTAATGGTTGGAGC-3' and reverse, 5'-CTGTGGCTCTATGGGTTGCT-3'; DR5 promoter site 3 - forward, $5^{\prime}$-GAGGGAAATCTTATATTACAG- $3^{\prime}$ and reverse, $5^{\prime}$-TCA GGTCCTAAAAGAGGAC-3'. Additionally, we used an unrelated sequence in the GAPDH gene as a negative control. ${ }^{49}$

Real-time quantitative RT-PCR. Total RNA was extracted using the RNeasy Mini Kit and the RNase-Free DNase Set according to the manufacturer's protocol (Qiagen, Hombrechtikon, Switzerland). Total RNA was reverse transcribed using random primers (Roche Diagnostics (Schweiz) AG, Switzerland) and M-MLV reverse transcriptase (Promega). Taqman Gene Expression Assays for DR5, DR4, DcR1, DcR2 and CSF3R were Hs00366278_m1, Hs00269492_m1, Hs00182570_m1, Hs00174664_m1 and Hs00167918_m1, respectively. Specific primers and probes for HMBS and PU.1 have been reported. ${ }^{38}$ Data represent the mean \pm S.D. of at least three independent experiments.

Proximity ligation assay. To detect a possible interaction between endogenous PU.1 and p65, we used the DuoLink in situ PLA (Sigma) according to the manufacturer's protocol. Cells were fixed with $4 \%$ PFA followed by 10-min incubation with $0.1 \%$ Triton X-100 solution in PBS and further blocking with PBS-containing $1 \%$ BSA and $0.1 \%$ Tween. Cells were immunolabeled with the following primary antibodies: PU.1 (Santa Cruz; sc-365208) and p65 (no. 8242; Cell Signaling) for $1 \mathrm{~h}$ at room temperature. Secondary antibodies with attached PLA probes are supplied by the manufacturer. Then, we used confocal microscopy to detect protein-to-protein interaction at a 600 magnification. A fluorescence signal indicates that two proteins within cells are separated by $<40 \mathrm{~nm}$. Image analysis was performed using the ImageJ Software.

Apoptosis assays. Cells were grown in 6-well plates and treated with recombinant human TRAIL (rhTRAIL), idarubicin (Sigma), doxorubicin (Pfizer AG, Switzerland), ABT-199 or with NF- $\kappa$ B inhibitors Bay 11-7082 and JSH-23 (Selleckchem, Switzerland) at concentrations indicated. At time points indicated cells were harvested and cell death was assessed by cleaved caspase-3, caspase8 and PARP immunoblotting as well as flow cytometry analysis of Annexin V-FITC (BioLegend, Switzerland)/propidium iodide-stained cell. Caspase-3/-7 activity was determined by a Caspase-Glo $3 / 7$ Assay (Promega AG) according to the manufacturer's instructions.

Flow cytometry. Cells were incubated with anti-DR5-biotin (Adipogene AG, Switzerland) or with an IgG isotype control for $30 \mathrm{~min}$ at $4{ }^{\circ} \mathrm{C}$. After incubation, cells were washed and incubated with streptavidin-PE (BioLegend) for 30 min at $4^{\circ} \mathrm{C}$. Data acquisition and analysis was carried out on a FACS LSR-II (BD Biosciences, Switzerland) using the FlowJo software (Ashland, OR, USA).

Statistical analysis. Nonparametric Mann-Whitney U-test were applied to compare the difference between the two groups using the program Prism Version 5 Software (GraphPad Software, Inc., Jolla, CA, USA). P-values $<0.05$ were considered to be statistically significant.

\section{Conflict of Interest}

The authors declare no conflict of interest.

Acknowledgements. We thank Dr. Nadia Corazza and Prof. Erik Vassella for their helpful inputs and reagents. This work was supported by grants from the Swiss National Science Foundation (31003A_143739 to MPT, 31003A_149387 to TK and PBBEP3_146108 to EAF), the German Science Foundation (BR 3369/5, INST 38/498-1 and INST 38/500-1 to TB) and the NIH (1R01HL116221-01 to BET).

\section{Author contributions}

$\mathrm{AH}, \mathrm{MH}$ and DKS conducted the experiments. AH drafted the article. EAF, TB, TK, SF and BET instigated the experimental design, provided essential reagents as well as preliminary results, and revised the drafted article. MPT designed the project, wrote the paper and gave final approval of the submitted manuscript.

1. Tenen DG, Hromas R, Licht JD, Zhang DE. Transcription factors, normal myeloid development, and leukemia. Blood 1997; 90: 489-519.

2. Simon MC, Olson M, Scott E, Hack A, Su G, Singh H. Terminal myeloid gene expression and differentiation requires the transcription factor PU.1. Curr Top Microbiol Immunol 1996; 211: 113-119.

3. Oikawa T, Yamada T, Kihara-Negishi F, Yamamoto H, Kondoh N, Hitomi Y et al. The role of Ets family transcription factor PU.1 in hematopoietic cell differentiation, proliferation and apoptosis. Cell Death Differ 1999; 6: 599-608.

4. Dahl R, Simon MC. The importance of PU.1 concentration in hematopoietic lineage commitment and maturation. Blood Cells Mol Dis 2003; 31: 229-233.

5. Mueller BU, Pabst T, Fos J, Petkovic V, Fey MF, Asou N et al. ATRA resolves the differentiation block in $\mathrm{t}(15 ; 17)$ acute myeloid leukemia by restoring PU.1 expression. Blood 2006; 107: 3330-3338.

6. Vangala RK, Heiss-Neumann MS, Rangatia JS, Singh SM, Schoch C, Tenen DG et al. The myeloid master regulator transcription factor PU.1 is inactivated by AML1-ETO in $t(8 ; 21)$ myeloid leukemia. Blood 2003; 101: 270-277.

7. Ridinger-Saison M, Evanno E, Gallais I, Rimmelé P, Selimoglu-Buet D, Sapharikas E et al. Epigenetic silencing of Bim transcription by Spi-1/PU.1 promotes apoptosis resistance in leukaemia. Cell Death Differ 2013; 20: 1268-1278.

8. Jenal M, Batliner J, Reddy VA, Haferlach T, Tobler A, Fey MF et al. The anti-apoptotic gene BCL2A1 is a novel transcriptional target of PU.1. Leukemia 2010; 24: 1073-1076.

9. Staber PB, Zhang P, Ye M, Welner RS, Nombela-Arrieta C, Bach C et al. Sustained PU.1 levels balance cell-cycle regulators to prevent exhaustion of adult hematopoietic stem cells. Mol Cell 2013; 49: 934-946.

10. Brigger D, Torbett BE, Chen J, Fey MF, Tschan MP. Inhibition of GATE-16 attenuates ATRAinduced neutrophil differentiation of APL cells and interferes with autophagosome formation. Biochem Biophys Res Commun 2013; 438: 283-288.

11. Haimovici A, Brigger D, Torbett BE, Fey MF, Tschan MP. Induction of the autophagy-associated gene MAP1S via PU.1 supports APL differentiation. Leuk Res 2014; 38: 1041-1047.

12. Brigger D, Proikas-Cezanne T, Tschan MP. WIPI-dependent autophagy during neutrophil differentiation of NB4 acute promyelocytic leukemia cells. Cell Death Dis 2014; 5: e1315.

13. Walczak H, Miller RE, Ariail K, Gliniak B, Griffith TS, Kubin M et al. Tumoricidal activity of tumor necrosis factor-related apoptosis-inducing ligand in vivo. Nat Med 1999; 5: 157-163.

14. Lemke J, Karstedt von S, Zinngrebe J, Walczak H. Getting TRAIL back on track for cancer therapy. Cell Death Differ 2014; 21: 1350-1364.

15. Azijli K, Weyhenmeyer B, Peters GJ, de Jong S, Kruyt FAE. Non-canonical kinase signaling by the death ligand TRAIL in cancer cells: discord in the death receptor family. Cell Death Differ 2013; 20: 858-868. 
16. Kischkel FC, Lawrence DA, Chuntharapai A, Schow P, Kim KJ, Ashkenazi A. Apo2 L/TRAILdependent recruitment of endogenous FADD and caspase- 8 to death receptors 4 and 5 . Immunity 2000; 12: 611-620.

17. Krueger A, Schmitz I, Baumann S, Krammer PH, Kirchhoff S. Cellular FLICE-inhibitory protein splice variants inhibit different steps of caspase-8 activation at the CD95 deathinducing signaling complex. J Biol Chem 2001; 276: 20633-20640.

18. LeBlanc H, Lawrence D, Varfolomeev E, Totpal K, Morlan J, Schow P et al. Tumor-cell resistance to death receptor-induced apoptosis through mutational inactivation of the proapoptotic Bcl-2 homolog Bax. Nat Med 2002; 8: 274-281.

19. Munshi A, Pappas G, Honda T, McDonnell TJ, Younes A, Li Y et al. TRAIL (APO-2L) induces apoptosis in human prostate cancer cells that is inhibitable by Bcl-2. Oncogene 2001; 20: 3757-3765.

20. Clohessy JG, Zhuang J, de Boer J, Gil-Gómez G, Brady HJM. Mcl-1 interacts with truncated Bid and inhibits its induction of cytochrome $c$ release and its role in receptor-mediated apoptosis. J Biol Chem 2006; 281: 5750-5759.

21. Schneider P, Thome M, Burns K, Bodmer JL, Hofmann K, Kataoka T et al. TRAIL receptors 1 (DR4) and 2 (DR5) signal FADD-dependent apoptosis and activate NF-kappaB. Immunity 1997; 7: 831-836.

22. Chaudhary PM, Eby M, Jasmin A, Bookwalter A, Murray J, Hood L. Death receptor 5 , a new member of the TNFR family, and DR4 induce FADD-dependent apoptosis and activate the NF-kappaB pathway. Immunity 1997; 7: 821-830v

23. Ricci MS, Kim S-H, Ogi K, Plastaras JP, Ling J, Wang W et al. Reduction of TRAlL-induced Mcl-1 and cIAP2 by c-Myc or sorafenib sensitizes resistant human cancer cells to TRAILinduced death. Cancer Cell 2007; 12: 66-80.

24. Lin Y, Devin A, Rodriguez Y, Liu ZG. Cleavage of the death domain kinase RIP by caspase-8 prompts TNF-induced apoptosis. Genes Dev 1999; 13: 2514-2526.

25. Schönheit J, Kuhl C, Gebhardt ML, Klett FF, Riemke P, Scheller M et al. PU.1 level-directed chromatin structure remodeling at the Irf8 gene drives dendritic cell commitment. Cell Rep 2013; 3: 1617-1628.

26. Smith LT, Hohaus S, Gonzalez DA, Dziennis SE, Tenen DG. PU.1 (Spi-1) and C/EBP alpha regulate the granulocyte colony-stimulating factor receptor promoter in myeloid cells. Blood 1996; 88: 1234v-1247v.

27. Kuffel MJ, Ames MM. Comparative resistance of idarubicin, doxorubicin and their C-13 alcohol metabolites in human MDR1 transfected NIH-3T3 cells. Cancer Chemother Pharmacol 1995; 36: 223-226.

28. Bonadies N, Neururer C, Steege A, Vallabhapurapu S, Pabst T, Mueller BU. PU.1 is regulated by NF-kappaB through a novel binding site in a $17 \mathrm{~kb}$ upstream enhancer element. Oncogene 2010; 29: 1062-1072.

29. Jin F, Li Y, Ren B, Natarajan R. PU.1 and C/EBP(alpha) synergistically program distinct response to NF-kappaB activation through establishing monocyte specific enhancers. Proc Natl Acad Sci USA 2011; 108: 5290-5295.

30. Li SKH, Abbas AK, Solomon LA, Groux GMN, DeKoter RP. Nfkb1 activation by the E26 transformation-specific transcription factors PU.1 and Spi-B promotes Toll-like receptormediated splenic B cell proliferation. Mol Cell Biol 2015; 35: 1619-1632.

31. Paz-Priel I, Cai DH, Wang D, Kowalski J, Blackford A, Liu H et al. CCAAT/enhancer binding protein alpha (C/EBPalpha) and C/EBPalpha myeloid oncoproteins induce bcl-2 via interaction of their basic regions with nuclear factor-kappaB p50. Mol Cancer Res 2005; 3: 585-596.
32. Shen $\mathrm{CH}$, Stavnezer J. Interaction of stat6 and NF-kappaB: direct association and synergistic activation of interleukin-4-induced transcription. Mol Cell Biol 1998; 18: 3395-3404.

33. Micheau O, Lens S, Gaide O, Alevizopoulos K, Tschopp J. NF-kappaB signals induce the expression of c-FLIP. Mol Cell Biol 2001; 21: 5299-5305v.

34. Liu H, Yang J, Yuan Y, Xia Z, Chen M, Xie L et al. Regulation of Mcl-1 by constitutive activation of NF-кB contributes to cell viability in human esophageal squamous cell carcinoma cells. BMC Cancer 2014; 14: 98v.

35. Turner DJ, Alaish SM, Zou T, Rao JN, Wang J-Y, Strauch ED. Bile salts induce resistance 0 apoptosis through NF-kappaB-mediated XIAP expression. Ann Surg 2007; 245: 415-425.

36. Tatetsu H, Ueno S, Hata H, Yamada Y, Takeya M, Mitsuya H et al. Down-regulation of PU.1 by methylation of distal regulatory elements and the promoter is required for myeloma cell growth. Cancer Res 2007; 67: 5328-5336.

37. Ueno S, Tatetsu H, Hata H, lino T, Niro H, Akashi $\mathrm{K}$ et al. PU.1 induces apoptosis in myeloma cells through direct transactivation of TRAIL. Oncogene 2009; 28: 4116-4125.

38. Tschan MP, Reddy VA, Ress A, Arvidsson G, Fey MF, Torbett BE. PU. 1 binding to the p53 family of tumor suppressors impairs their transcriptional activity. Oncogene 2008; 27 3489-3493.

39. Ottina $E$, Tischner D, Herold MJ, Villunger A. A1/Bfl-1 in leukocyte development and cell death. Exp Cell Res 2012; 318: 1291-1303.

40. Zong WX, Edelstein LC, Chen C, Bash J, Gélinas C. The prosurvival Bcl-2 homolog Bfl-1/A1 is a direct transcriptional target of NF-kappaB that blocks TNFalpha-induced apoptosis. Genes Dev 1999; 13: 382-387.

41. Zhao M, Duan X-F, Wen D-H, Chen G-Q. PU.1, a novel caspase-3 substrate, partially contributes to chemotherapeutic agents-induced apoptosis in leukemic cells. Biochem Biophys Res Commun 2009; 382: 508-513.

42. Altucci L, Rossin A, Raffelsberger W, Reitmair A, Chomienne C, Gronemeyer H. Retinoic acid-induced apoptosis in leukemia cells is mediated by paracrine action of tumor-selective death ligand TRAIL. Nat Med 2001; 7: 680-686.

43. Gilmore TD, Herscovitch M. Inhibitors of NF-kappaB signaling: 785 and counting. Oncogene 2006; 25: 6887-6899.

44. Humbert M, Federzoni EA, Britschgi A, Schläfli AM, Valk PJM, Kaufmann T et al. The tumor suppressor gene DAPK2 is induced by the myeloid transcription factors PU.1 and C/EBP $\alpha$ during granulocytic differentiation but repressed by PML-RAR $\alpha$ in APL. J Leukoc Biol 2014; 95: 83-93.

45. Federzoni EA, Valk PJM, Torbett BE, Haferlach T, Löwenberg B, Fey MF et al. PU.1 is linking the glycolytic enzyme HK3 in neutrophil differentiation and survival of APL cells. Blood 2012; 119: 4963-4970.

46. Tschan MP, Fischer KM, Fung VS, Pirnia F, Borner MM, Fey MF et al. Alternative splicing of the human cyclin D-binding Myb-like protein (hDMP1) yields a truncated protein isoform that alters macrophage differentiation patterns. J Biol Chem 2003; 278: 42750-42760.

47. Gilda JE, Gomes AV. Western blotting using in-gel protein labeling as a normalization control: stain-free technology. Methods Mol Biol 2015; 1295: 381-391.

48. Taylor SC, Berkelman T, Yadav G, Hammond M. A defined methodology for reliable quantification of Western blot data. Mol Biotechnol 2013; 55: 217-226.

49. Kaeser MD, Iggo RD. Chromatin immunoprecipitation analysis fails to support the latency model for regulation of p53 DNA binding activity in vivo. Proc Natl Acad Sci USA 2002; 99: 95-100.

Supplementary Information accompanies this paper on Cell Death and Differentiation website (http://www.nature.com/cdd) 